\title{
28. The use of aero-magnetics to enhance a numerical groundwater model of the Lagan Valley aquifer, Northern Ireland
}

\author{
Neil Dickson, ${ }^{\mathrm{I}}$ Jean-Christophe Comte, ${ }^{2}$ Jennifer \\ MCKINLEY $^{\mathrm{I}}$ AND UlRich OfTERdingeR ${ }^{\mathrm{I}}$
}

How to cite this chapter:

Dickson, N.E.M., Comte, J.-C., McKinley, J.M. and Ofterdinger, U., 2016 'The use of aero-magnetics to enhance a numerical groundwater model of the Lagan Valley aquifer, Northern Ireland' in M.E. Young (ed.), Unearthed: impacts of the Tellus surveys of the north of Ireland. Dublin. Royal Irish Academy.

DOI:10.3318/ 978-1-908996-88-6.ch28
Numerical modelling of aquifers is a standard process in the sustainable management of groundwater resources. To be reliable, a groundwater model requires an accurate geological framework, particularly where structure is complex. The Lagan Valley aquifer near Belfast is an example of an otherwise generally homogenous sandstone aquifer intruded by extensive swarms of low-permeability igneous dykes. The dissection of the aquifer by these dykes affects groundwater flow direction and borehole yield. We have used the Tellus aeromagnetic data to map the extent of these dykes and so improve the geometrical parameterisation of the models. Two methods are described for incorporating the effect of the dykes: a visual deterministic approach and a stochastic approach using Multiple Point Statistics. Both approaches resulted in models that significantly improved matches to observed groundwater levels and flow directions, demonstrating the value of aero-magnetic data for constraining these models.

\section{INTRODUCTION: GROUNDWATER MODELS AND MANAGEMENT}

Under the EU Water Framework Directive governments are required to characterise and monitor aquifers to ensure that these unseen but valuable resources are protected and managed sustainably. Efficient management of groundwater resources is facilitated by numerical modelling, which allows us to estimate rates of abstraction that should be sustainable. Numerical computer modelling is a well-established means of predicting the performance of an aquifer in terms of measured or estimated parameters, including its

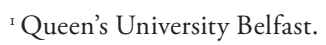

${ }^{2}$ University of Aberdeen. 


\section{Dickson et al.}

geometrical dimensions, natural and artificial recharge, permeability, porosity and hydraulic conductivity. The validity of any model depends heavily on assumptions made about unseen or unmeasurable characteristics, particularly the internal geological structure of the aquifer, which affects storage capacity and rates of internal flow. Modelling is more reliable where the aquifer is geologically homogenous; where the lithology is complex, faulted or intruded the assumptions break down.

In this study we examine how the results of the Tellus aero-magnetic survey can improve our knowledge of the geological framework and 'parameterisation' of our numerical model of the Lagan Valley aquifer, an important freshwater resource for Northern Ireland.

\section{Groundwater modelling and the problem of heterogeneity}

Mathematical groundwater models are effective tools which enable us to describe the flow processes in accordance with well-established governing equations. Due to the complexity of aquifer systems, in terms of geometry, properties and boundary conditions, iterative numerical techniques are necessary to solve these complex equations. Modellers must be careful not to over-simplify the conceptual model, as an unrealistic model inevitably leads to a poor interpretation. Modelling can facilitate the testing of several hydrogeological hypotheses but naturally the quality of the output is dependent on that of the input. Although models with structural heterogeneity contain greater levels of uncertainty, there is scope for reducing this by using the results of the aero-magnetics to map the extent of heterogeneity arising from the presence of impermeable dykes.

Mapping the spatial distribution of heterogeneity is the first step in assigning flow properties and parameterising a numerical model. Aerial imagery, remote sensing, modern digital terrain models and geological mapping can all help to identify heterogeneity or complexity, although usually on a regional or kilometre scale. The most effective spatial mapping results from combining various regional and local approaches, including field mapping, hydraulic testing of wells and geophysics, to improve accuracy and verify aerially mapped structures.

Geophysical techniques are commonly used in hydrogeological investigations. As well as the use of magnetics for mapping structures, as in this case, various ground-based methods are routinely applied for mapping the dimensions of aquifers and aquicludes (electrical, electromagnetic and seismic methods) and variations in water quality, including saline intrusion (electrical and electromagnetics). Some methods, notably magnetics and electromagnetics, are readily transposed to airborne systems for rapid, regional scale survey, although with some loss of resolution compared with ground measurements. Brunner $e t$ al. (2007) have demonstrated the advantages of linking airborne geophysics and remote sensing with numerical groundwater flow models for mapping faults and dykes, estimating aquifer thickness and mapping soil salinisation. 


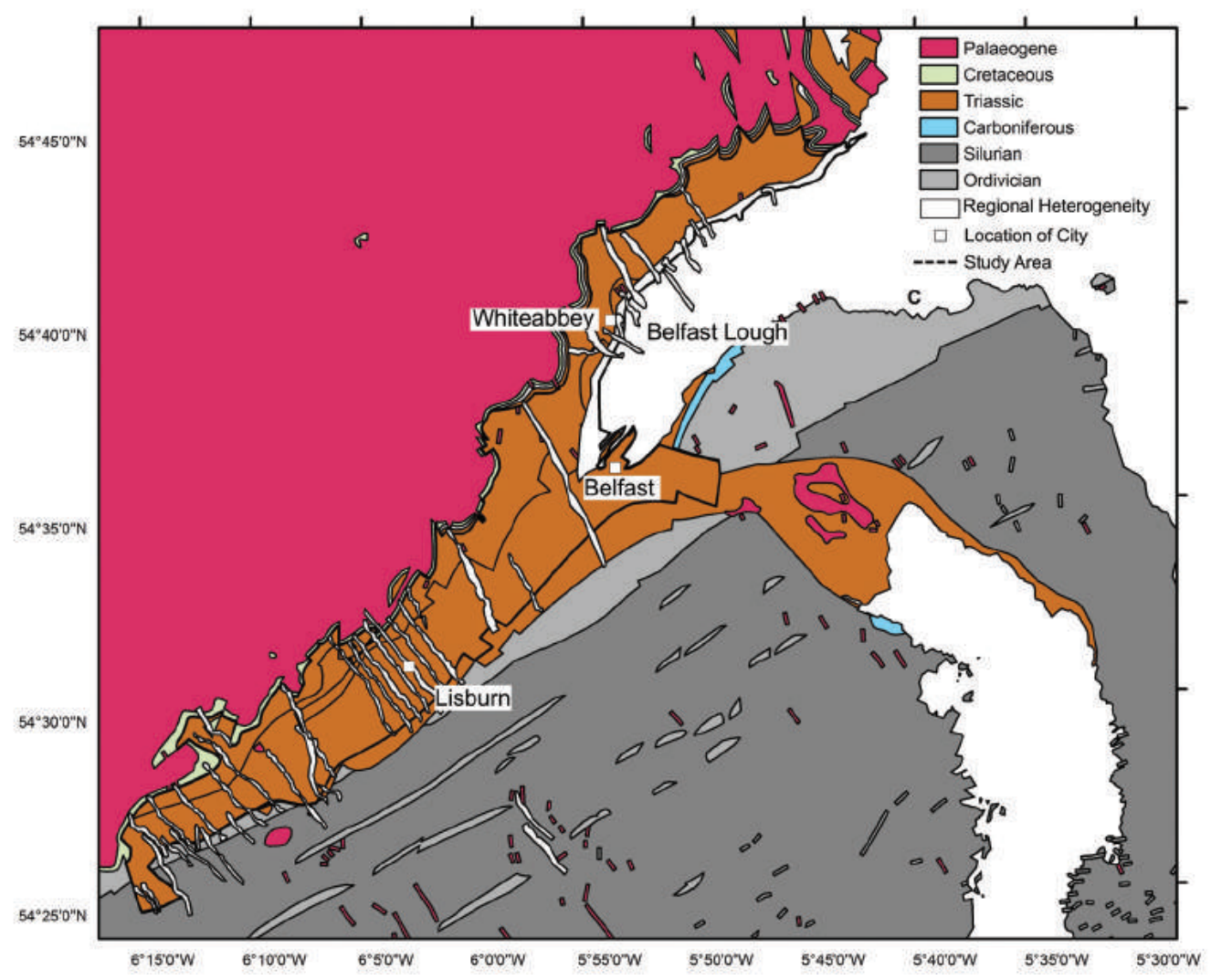

Figure 28.1. The geology around Belfast, showing digitised regional heterogeneities (dykes) as determined deterministically from the aerial magnetics. The black line is the outline of the Triassic sequence that includes the Sherwood Sandstone aquifer.

\section{Modelling the Lagan Valley aQuifer}

The Lagan Valley, extending south-west from Belfast, is a typical U-shaped valley formed by glaciation during the Last Glacial Maximum of the Quaternary period (Fig. 28.1). The aquifer lies in the Triassic Sherwood Sandstone Group (SSG), which dips to the north-west beneath the overlying and relatively impermeable Triassic Mercia Mudstone. Remnant glacial till and drift material overlie these formations. The SSG is a porous, moderately permeable aquifer of high productivity, yielding approximately 30-50 $1 \mathrm{~s}^{-1}$. Historically, the aquifer was a significant source of public water supply and it still supplies water to local industry and hospitals. It remains an important strategic resource that if required could supply Belfast in the future. The aquifer has been extensively studied, originally notably by Hartley (1935) and by Bennett (1975).

The aquifer is geologically complicated by a network of near-vertical dolerite dykes that were intruded during the Palaeogene period. These are the remains of the hypovolcanic system through which the basalts of the Antrim Lava Group erupted (Cooper and Johnson, 2004). The basalts have since been eroded from the valley itself. These dykes are widespread, are generally of relatively low permeability and act as obstacles to underground water flow in the aquifer. Previous isotropic hydrogeological models (e.g. Cronin, 2000) did not quantify the effect of these dykes, although their effect was noted. Recent ground surveys have investigated their effects on the aquifer and confirmed that the dykes hinder 


\section{Dickson et al.}

local groundwater flow, as demonstrated at a coastal site where a dyke clearly impedes salt water intrusion (Wilson, 2011).

As these dykes are well magnetised, we can map their extent from the aero-magnetic results of the Tellus airborne geophysical survey of 2005-6 (Young and Donald, 2013; Hodgson and Young, Chapter 2, this volume).

\section{USING TELLUS MAgNetiCS TO IMPROVE MODEL PARAMETERISATION}

The airborne geophysical survey of the Tellus Project provided continuous magnetic field data over all Northern Ireland. Magnetic data were acquired at 55-60 m above ground level at approximately $7 \mathrm{~m}$ intervals along traverse lines $200 \mathrm{~m}$ apart. These data of the total magnetic intensity, after gridding onto a regular Cartesian net, may be readily transformed by the judicious application of a range of mathematical filters to enhance or suppress different components of the signal. For example, man-made or other surface noise can be reduced; signals from different depths can be separated; and the asymmetry inherent in the shape of the magnetic anomaly can be corrected. Chacksfield (2007) presented several of these for the Tellus data. Here we work with the total magnetic intensity reduced-topole (RTP) and the tilt-angle derivative of the RTP (Salem et al., 2008), as calculated using Geosoft ${ }^{\mathrm{Tm}}$ software. These transformations improve the resolution and the precision of source location.

We consider a part of the Lagan Valley centred approximately $10 \mathrm{~km}$ south-west of Belfast (Figs 28.1 and 28.2). Here the RTP image shows a swarm of dykes striking northwest across the Lagan Valley and intruding the Triassic and underlying Permian and Silurian sediments. Some dykes can be seen to penetrate (and therefore post-date) the Antrim lavas to the north-west, which themselves are strongly magnetised. Other dykes appear to be truncated at the lava contact, and are therefore interpreted to predate the lavas, which now cover them and mask their magnetic expressions (Cooper et al., 2012). The magnetic expression of the dykes is also partially obscured by the southern extent of the Antrim lava anomaly over the Mercia Mudstone.

We can use these magnetic results in two ways to improve the geological framework of our numerical aquifer models: (1) deterministic interpretation of dyke distribution by visual analysis of magnetic signatures; and (2) direct geostatistical analysis of the continuous data set. The latter method can screen out the 'noise' that is inherent in magnetic data as well as possible human bias in the visual interpretation.

\section{Resolution of aero-magnetic surveys}

Aero-magnetic survey merges the magnetic anomalies of multiple narrow sources, such as magnetised dykes. The magnetic method cannot resolve multiple narrow sources within a width less than about the height of the sensor, or around $60 \mathrm{~m}$ for our airborne data. Field mapping and more detailed ground survey is necessary to resolve the individual dyke anomalies. Ground magnetic traversing across a single aero-magnetic dyke anomaly in 
A

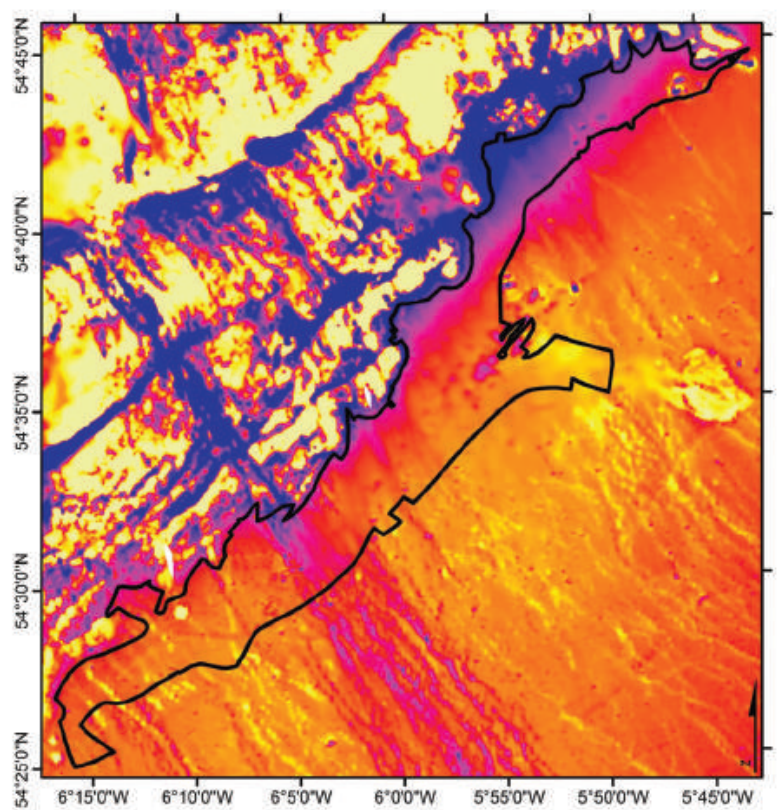

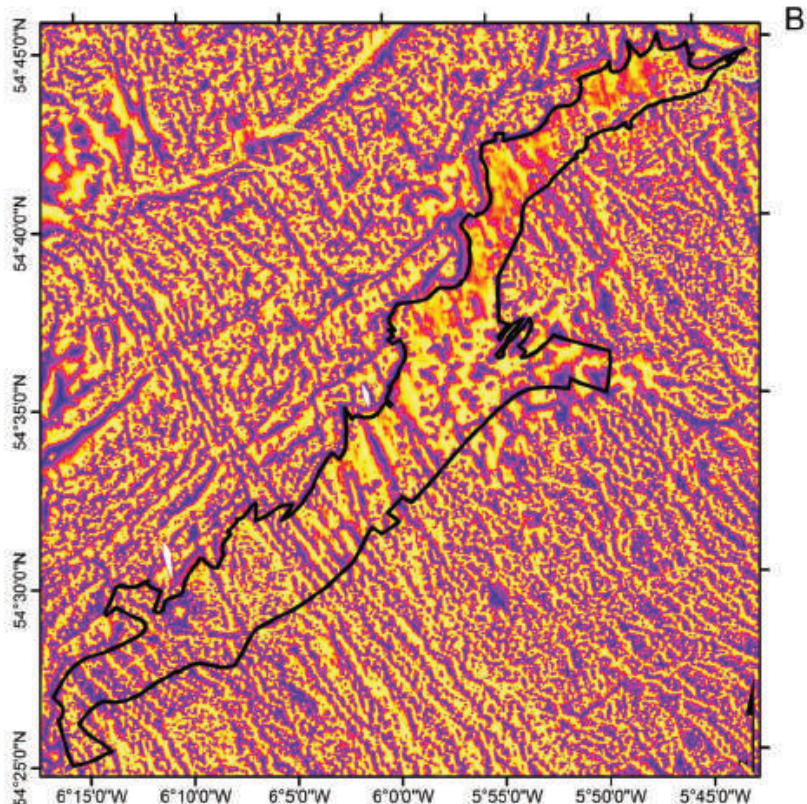

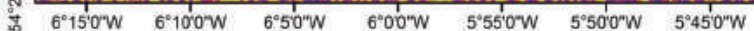

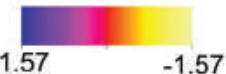

Outline of Triassic Sediments
RTP Tilt Derivative Magnetics

(Radians)
Figure 28.2. (A) Reducedto-pole (RTP) total magnetic intensity (nT) for the area around the Lagan Valley; (B) tilt derivative of RTP (radians). this area typically reveals several individual dykes of $0.5-10 \mathrm{~m}$ width. This heterogeneity observed at ground level (or small scale) provides the quantitative data that can be translated statistically into a model of regional-scale heterogeneity. At the larger scale, the simulated heterogeneity is composed of several smaller heterogeneities (dykes), each with particular hydrogeophysical properties and anisotropy properties, which are in turn composed of even smaller heterogeneities (i.e. fractures), which can be seen in outcrop. Therefore, although the aero-magnetic anomalies are too broad to define small, field-scale heterogeneities, this limitation in resolution can be overcome either by using a visual, deterministic upscaling technique as detailed in Dickson et al. (2014) or by a direct geostatistical manipulation of the continuous data (Dickson et al., 2015). These two alternatives are described below.

\section{Deterministic parameterisation}

Deterministic parametrisation assumes an understanding of the geological environment, where the structure or processes are defined and known within a degree of certainty. In our example case, visual analysis of the magnetic imagery and personal judgement were used to delineate regional heterogeneities (Fig. 28.1), based on the polarity and linearity of the magnetic anomalies. 

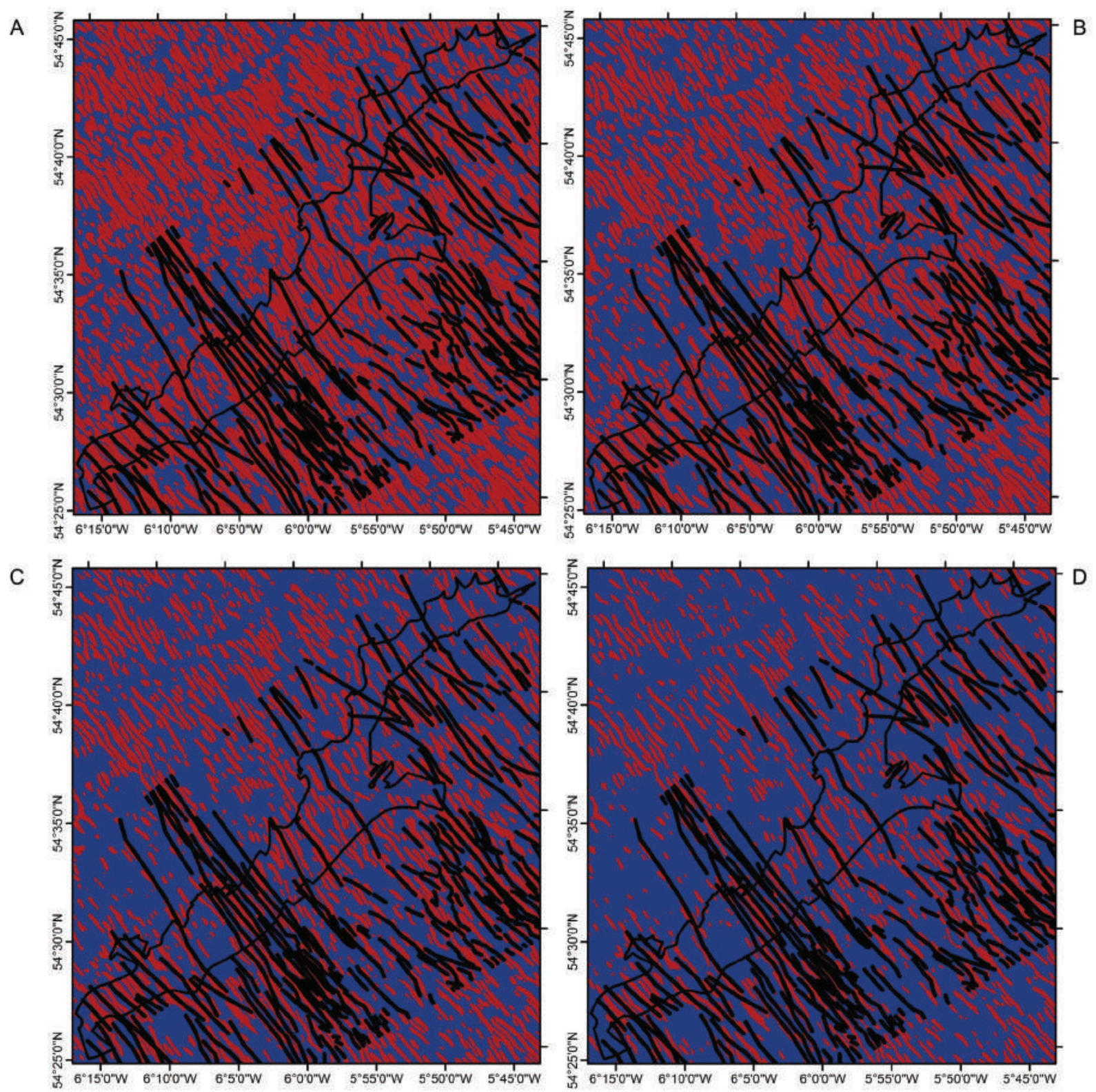

Sandstone (0)

Regional Dyke (1)

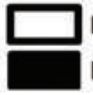

Lagan Valley Boundary

Published Dyke Locations

Examination of the local and regional magnetic imagery indicated that a representative regional heterogeneity would be equivalent to a grouping of local heterogeneities. Therefore, equivalent (upscaled) hydrogeological properties were calculated using the method of Cardwell and Parsons (1945), which provides a means of extending field-scale observations
Figure 28.3. MPS simulations for the area of Fig. 28.2 for different probability thresholds: (A) 50\%; (B) 60\%; (C) $70 \%$; (D) $80 \%$. Dykes after Cooper $e t$ al. (2012). 
to a regional level. The aero-magnetics were used to determine an approximate dyke density throughout the wider area by correlating the density of 13 observed dyke outcrops with the aero-magnetic signals at these points. Using this approach, a highly positive correlation was observed $\left(r^{2}=0.9518\right)$, indicating that the integrated magnetic signal varies according to how many field scale dykes are merged. By processing the dyke density output with the method of Cardwell and Parsons (1945), hydraulic conductivity was determined for the wider area.

\section{Statistical parameterisation}

The alternative, statistical application used here is a development of the stochastic process of Multiple Point Statistics (MPS) (Hu and Chugunova, 2008). We used a form of this process, the Direct Sampling Method, using the DeeSse computer code from Mariethoz et al. (2010).

In the application of MPS, a training image (TI) is chosen, which is a binary (i.e. sandstone $=0$, dyke $=1$ ) conceptual understanding of a pattern representative of an area of data. The process then searches for replication of this trend or pattern over the full survey area (known as the simulation grid) to statistically distribute a new understanding of the pattern or trend, displaying the result as a probability of occurrence. In our example, a conceptual understanding of dyke trend provided the initial TI conceptualisation. Subsequently, the aero-magnetics data were transformed into an additional TI (which was continuous in design) and was combined with the original binary TI. Combining the TIs creates a relationship between a binary value and the overlapping continuous magnetics value. In this example, a 1 should correspond to highly positive or negative magnetics values.

The simulation grid used here is the tilt-derivative of the RTP data. Using the binary TI conceptualisation of dyke trend and the corresponding aero-magnetics TI equivalent, the DeeSse code analyses the trends found in the TI and searches for similar trends within the RTP data. The resulting output is a probability map created with the software SGeMS (Remy et al. 2009), an effective tool for viewing the code output. The probability map portrays dyke occurrence where the code has simulated the presence of a dyke within a set number of simulations.

This output is a continuous statistical interpretation of dyke trends throughout the region (Fig. 28.3), as opposed to the deterministic, human interpretation. As 6000 simulations were created, it was difficult to determine which probability map was most accurate and related to the known heterogeneity locations. Therefore, probability thresholds (50\%, 60\%, 70\% and 80\%; see Fig. 28.3) were applied to the MPS simulations and resulting maps were compared with the interpretations of Cooper et al. (2012) and Dickson et al. (2014) to evaluate the MPS simulations and determine which matched the dyke trend direction, continuity and thickness. The statistical output was transformed 
A polated observations

\section{Isotropic Model}

(Cronin, 2000)

Deterministic Estimation (Dickson et al.,2014)
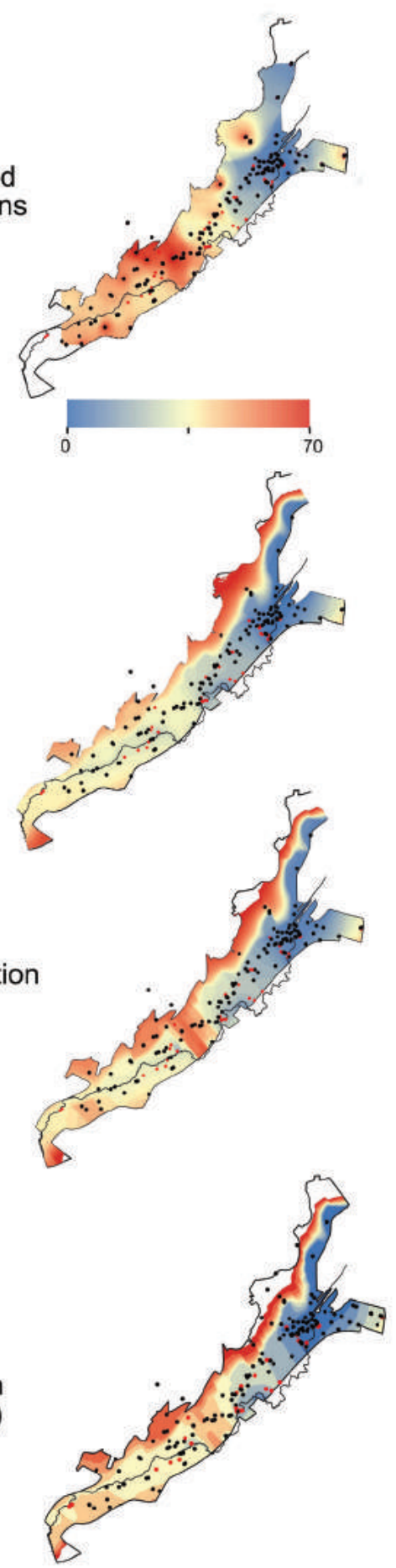

Groundwater heads

$(\mathrm{m} / \mathrm{msl})$

Calculated vs observed heads
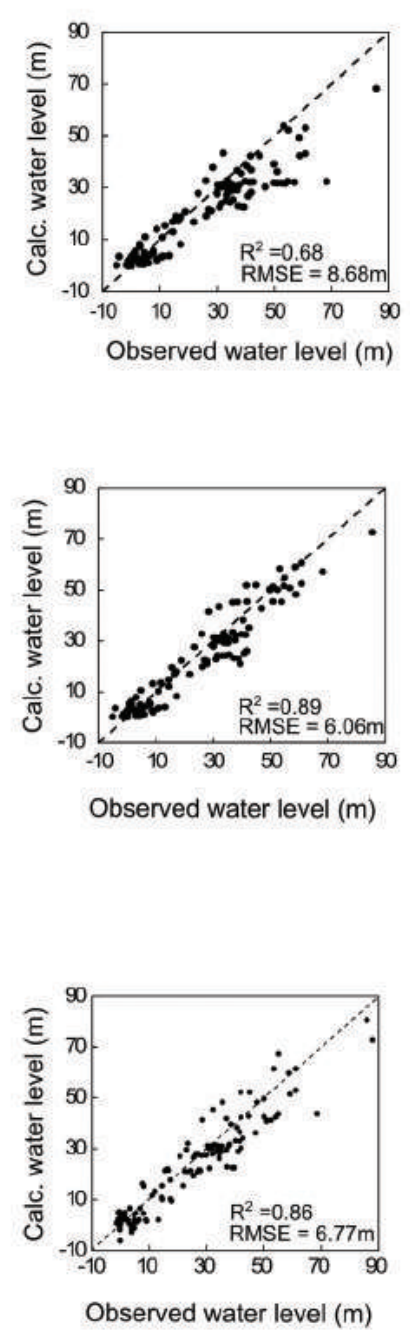
Figure 28.4. Maps of (A) interpolated static water levels observed in boreholes within the aquifer and (B) simulated groundwater heads (masl) for the isotropic, deterministic and statistical analyses. Model regressions show the fit of the models and the root-meansquare error values. into a groundwater model parameter (hydraulic conductivity) using the details of the 'Deterministic estimation' section.

\section{RESULTS}

The developed groundwater model (constructed using the industry-standard software FEFLOW $^{\mathrm{TM}}$ 6.1) included the Lagan Valley aquifer and the overlying Mercia mudstone to provide model boundary conditions. The Mercia mudstone was subsequently deleted from the model domain before analysis. When the results of the deterministic simulation were incorporated into the groundwater model, a significant positive correlation $\left(r^{2}=\right.$ 0.89) resulted between actual and simulated groundwater levels at the borehole locations shown in Fig. 28.4a, with an error of only $6.06 \mathrm{~m}$. The simulated water levels using this deterministic model are shown in Fig. 28.4b. As observed at the field scale, the dykes acted as barriers which are particularly evident in the water levels around Lisburn where the dykes are particularly dense. Actual water levels were higher than the simulated levels. The groundwater model demonstrates the dyke compartmentalisation through a change of groundwater flow direction, which trends parallel to the dyke locations and perpendicular to the average regional groundwater flow direction. Average flow direction is northeast at $46^{\circ}$, which agrees with the conceptual model.

The stochastic simulation also produces a very significant positive correlation $\left(r^{2}=\right.$ 0.86) with an error of $6.77 \mathrm{~m}$ (Fig. 28.4b). This result indicates that the MPS realisations are well constrained by the geophysical interpretation and filter out the magnetic overprint of the Antrim lava flows to the north and magnetic noise of urban areas, both of which suppress the dyke anomalies. This is most likely a result of the use of continuous auxiliary data instead of only the limited constraints of a number of boreholes. As a result, the integration of the MPS results provides a more comprehensive distribution of dyke occurrences, with more linear continuity, which increases their influence on groundwater flow. The presence of additional dykes increases compartmentalisation and therefore generally results in higher water table. The MPS method is similar to the deterministic method but with a statistical implementation of dyke location, particularly for locations that are obscured by noise or peripheral anomalies in the airborne data.

Both the deterministic and stochastic approaches show improvements in estimating water levels compared to the earlier isotropic model of Fig. $28.4 \mathrm{~b}\left(r^{2}=0.68\right)$, thanks to the improvement provided by the aero-magnetic mapping of dykes. With regard to flow, however, the simulated flow directions produce some similarities and some distinct differences. Along the length of the River Lagan flow directions appear similar between the isotropic and anisotropic models due to the strong connectivity to the aquifer and hydraulic gradients.

The largest differences in flow direction occur around the city of Lisburn at the dense swarm of simulated dykes. The effects are seen in both of the anisotropic models. Analysis indicates that the flow directions are parallel to the trend of the heterogeneity, i.e. the 


\section{Dickson et al.}

dykes are impermeable and force the groundwater to flow beside the heterogeneity in a broadly north-west direction. This is a distinct difference to the isotropic model, which portrays flow direction to be broadly to the east, towards Belfast Lough. It should be noted that in this area of dense simulated dykes, the River Lagan is not located within the SSG and does not have a significant effect.

At the mouth of the River Lagan flow angles are very similar in all models, showing a distinct trend towards Belfast Lough. Slightly sharper and more distinct flow direction variations are observed within the model created by the MPS method due to the code being better able to estimate the location of the dykes. The deterministic method struggled to define dyke locations in the urbanised area. However, the overall flow angles are broadly similar.

\section{GROUNDWATER MANAGEMENT IMPLICATIONS}

The improvement and enhancement of groundwater models using aero-magnetic and other geophysical methods to improve the geological parameters could significantly improve the reliability of predictions based on these models. More reliable estimates of safe yields are particularly important in stressed aquifers, where demand approaches or even exceeds recharge, although this is not the case for the Lagan Valley aquifer. Improved characterisation of the subsurface structure is also particularly important when using models to estimate the likely pathways of contaminants.

Through an improved understanding of borehole capture zones, the new model can assist in more accurate delineation of source protection zones for wells and provide guidance on where to install monitoring systems.

Testing the technique on other aquifers is encouraged as it could help improve the conceptual models of other groundwater bodies and thus serve the objectives of the Water Framework Directive for the protection, monitoring and sustainable use of groundwater resources. This would be especially useful in the many areas of Ireland with low-productivity, fractured aquifers.

\section{REFERENCES}

Bennett, J.R.P., 1976 The Lagan Valley: Hydrogeological Study. Open File Report 57. Belfast. Geological Survey of Northern Ireland.

Brunner, P., Hendricks Franssen, H.-.J, Kgotlhang, L., Bauer-Gottwein, P. and Kinzelbach W., 2007 'How can remote sensing contribute in groundwater modelling?', Hydrogeology Journal, 15, 5-18. http://dx.doi.org/10.1007/s10040-006-0127-z\#/page-1

Cardwell, W.T. and Parsons, R.L., 1945 'Average permeabilities of heterogeneous oil sands', Transactions of the American Institute of Mining, Metallurgical, and Petroleum Engineers Inc., 160, 1, 34-42.

Chacksfield, B.C., 2010 A Preliminary Interpretation of Tellus Airborne Magnetic and Electromagnetic Data for Northern Ireland. British Geological Survey Internal Report, IR/07/041. Available at http://nora.nerc.ac.uk/9812/. 
Cooper, M.R., Anderson, H., Walsh, J.J., Van Dam, C.L., Young, M.E., Earls, G. and Walker, A., 2012 'Palaoegene Alpine tectonics and Icelandic plume-related magmatism and deformation in Northern Ireland', Journal of the Geological Society, London, 169, 29-36. Available at http://nora.nerc.ac.uk/16421/. http://dx.doi.org/10.1144/0016-76492010-182.

Cooper, M.R. and Johnston, T.P., 2004 'Palaeogene intrusive igneous rocks', in W.I. Mitchell (ed.), The Geology of Northern Ireland: Our Natural Foundation. Second edition, 179-98. Belfast. Geological Survey of Northern Ireland.

Cronin, A.A., 2000 Groundwater Flow and Isotope Geochemical Modelling of the Triassic Sandstone Aquifer, Northern Ireland. Unpublished PhD thesis, School of Planning, Architecture and Civil Engineering, Queen's University, Belfast.

Dickson, N.E.M., Comte, J.-C., McKinley, J. and Ofterdinger, U., 2014 'Coupling ground and airborne geophysical data with upscaling techniques for regional groundwater modeling of heterogeneous aquifers: case study of a sedimentary aquifer intruded by volcanic dykes in Northern Ireland', Water Resources Research, 50, 10, 7984-8001. http://dx.doi.org/10.1002/2014WR015320.

Dickson, N.E.M., Comte, J.-C., Renard, P., Straubhaar, J., McKinley, J. and Ofterdinger, U., 2015 'A combined stochastic and geophysical aquifer analysis to constrain groundwater flow models', Hydrogeology Journal, 23, 5, 883-900. http://dx.doi.org/10.1007/s/10040-015-128-x.

Hartley, J.J., 1935 'The underground water resources of Northern Ireland. Institution of Civil Engineers (Northern Ireland Association)', paper presented to Belfast and District Association.

Hu, L.Y. and Chugunova, T., 2008 'Multiple-point geostatistics for modeling subsurface heterogeneity: a comprehensive review', Water Resources Research, 44, W11413, http://dx.doi.org/10.1029/2008WR006993.

Mariethoz, G., Renard, P. and Straubhaar, J., 2010 'The Direct Sampling method to perform multiple-point geostatistical simulations', Water Resources Research, 46, 11, W11536. http://dx.doi.org/10.1029/2008WR007621.

Remy, N., Boucher, A. and Wu, J. 2009 Applied Geostatistics with SGeMS: A User's Guide. New York. Cambridge University Press.

Salem, A., Williams, S., Fairhead, D., Smith, R. and Ravat, D., 2008 'Interpretation of magnetic data using tilt-angle derivatives', Geophysics, 73, 1, L1-L10. http://dx.doi.org/10.1190/1.2799992.

Wilson, C., 2011 Analysis of the Effect of Volcanic Dykes on Groundwater Flow in the Sherwood Sandstone Aquifer: Impacts on Piezometry, Salinity, and Attenuation of the Tidal Signal. Unpublished MSc thesis, School of Planning, Architecture and Civil Engineering, Queen's University, Belfast.

Young, M.E. and Donald, A.W. (eds), 2013 A Guide to the Tellus Data. Belfast. Geological Survey of Northern Ireland. Available at http://nora.nerc.ac.uk/509171/. 


\section{Table of Contents:}

\section{Prelim}

DOI:10.3318/978-1-908996-88-6.prelims

\section{Chapter 1}

The Tellus geosciences surveys of the north of Ireland: context, delivery and impacts

DOI:10.3318/978-1-908996-88-6.ch1

\section{Chapter 2}

The Tellus airborne geophysical surveys and results DOI:10.3318/978-1-908996-88-6.ch2

\section{Chapter 3}

The Tellus geochemical surveys, results and applications

DOI:10.3318/978-1-908996-88-6.ch3

\section{Chapter 4}

Stakeholder engagement for regional geoscientific surveying: the Tellus Border communications campaign

DOI:10.3318/978-1-908996-88-6.ch4

\section{Chapter 5}

Mineral resources and Tellus: the essential balance DOI:10.3318/978-1-908996-88-6.ch5

\section{Chapter 6}

Gold exploration in the north of Ireland: new targets from the Tellus Projects

DOI:10.3318/978-1-908996-88-6.ch6

\section{Chapter 7}

Using soil geochemistry to investigate gold and base metal distribution and dispersal in the glaciated north of Ireland

DOI:10.3318/978-1-908996-88-6.ch7

\section{Chapter 8}

Critical metals for hightechnology applications: mineral exploration potential in the north of Ireland DOI: 10.3318/978-1-908996-88-6.ch8

\section{Chapter 9}

A natural laboratory for critical metals investigations in the Mourne Mountains granites

DOI:10.3318/978-1-908996-88-6.ch9

\section{Chapter 10}

Geothermal potential of granitic rocks of the Mourne Mountains

DOI:10.3318/978-1-908996-88-6.ch10

\section{Chapter 11}

Shape and intrusion history of the Late Caledonian Newry Igneous Complex, Northern Ireland DOI:10.3318/978-1-908996-88-6.ch1 1

\section{Chapter 12}

Using Tellus data to enhance targeting of volcanogenic massive sulphide mineralisation in the Tyrone Igneous Complex

DOI:10.3318/978-1-908996-88-6.ch12

\section{Chapter 13}

The geological significance of electrical conductivity anomalies of the Ordovician- Silurian Moffat Shale Group, Northern Ireland DOI:10.3318/978-1-908996-88-6.ch13

\section{Chapter 14}

Faults, intrusions and flood basalts: the Cenozoic structure of the north of Ireland

DOI:10.3318/978-1-908996-88-6.ch14

\section{Chapter 15}

Information for agriculture from regional geochemical surveys: the example of soil $\mathrm{pH}$ in the Tellus and Tellus Border data

DOI:10.3318/978-1-908996-88-6.ch15

\section{Chapter 16}

An ecohydrological investigation of wetlands in the border counties of Ireland: a framework for a holistic understanding of wetland systems

DOI:10.3318/978-1-908996-88-6.ch16 
Chapter 17

Assessing nutrient enrichment risk to groundwaterdependent ecosystems in the border counties of Ireland DOI:10.3318/978-1-908996-88-6.ch17

\section{Chapter 18}

Mapping the terrestrial gamma radiation dose

DOI:10.3318/978-1-908996-88-6.ch18

\section{Chapter 19}

Soils and their radiometric characteristics

DOI:10.3318/978-1-908996-88-6.ch19

\section{Chapter 20}

Modelling in-house radon potential using Tellus data and geology to supplement inhouse radon measurements

DOI:10.3318/978-1-908996-88-6.ch20

\section{Chapter 21}

Determining geochemical threshold values from the Tellus data sets: the examples of zinc and iodine| DOI:10.3318/978-1-908996-88-6.ch21

\section{Chapter 22}

Identification of the geochemical signatures of diffuse pollution in the Tellus Border soil data set, using source apportionment

DOI:10.3318/978-1-908996-88-6.ch22

\section{Chapter 23}

Stream sediment background concentrations in mineralised catchments in Northern Ireland: assessment of 'pressures' on water bodies in fulfilment of Water Framework Directive objectives

DOI:10.3318/978-1-908996-88-6.ch23

\section{Chapter 24}

Mapping metallic contamination of soils in the Lower Foyle catchment

DOI:10.3318/978-1-908996-88-6.ch24

\section{Chapter 25}

Refining the human health risk assessment process in Northern Ireland through the use of oral bioaccessibility data

DOI:10.3318/978-1-908996-88-6.ch25

\section{Chapter 26}

Combining environmental and medical data sets to explore potential associations between environmental factors and health: policy implications for human health risk assessments

DOI:10.3318/978-1-908996-88-6.ch26

\section{Chapter 27}

Mapping a waste disposal site using Tellus airborne geophysical data

DOI:10.3318/978-1-908996-88-6.ch27

\section{Chapter 28}

The use of aero-magnetics to enhance a numerical groundwater model of the Lagan Valley aquifer,

Northern Ireland

DOI:10.3318/978-1-908996-88-6.ch28

\section{Chapter 29}

Carbon sequestration in the soils of Northern Ireland: potential based on mineralogical controls

DOI:10.3318/978-1-908996-88-6.ch29

\section{Chapter 30}

Spatial distribution of soil geochemistry in geoforensics DOI:10.3318/978-1-908996-88-6.ch30

\section{End matter}

DOI:10.3318/978-1-908996-88-6.endmatter 
Unearthed: impacts of the Tellus surveys of the north of Ireland

First published in 2016 by the

Royal Irish Academy

19 Dawson Street

Dublin 2

www.ria.ie

Copyright (C) 2016 Royal Irish Academy

ISBN: 978-1-908996-87-9

The articles in this book are open access and distributed under the terms of the Creative Commons Attribution 4.0 licence, which permits unrestricted use, distribution and reproduction in any medium, provided the original authors and source are credited. To view a copy of this licence, visit https://creativecommons.org/licenses/by/4.0/

Except where noted:

Geological mapping for Northern Ireland / Tellus data are provided by the Geological Survey of Northern Ireland.

Geological mapping for Ireland / Tellus Border data are provided by the Geological Survey of Ireland.

Topographic mapping for Northern Ireland is derived from Land and Propery Services Open Data and contains public sector information licensed under the Open Government Licence v3.0. (http://www.nationalarchives.gov.uk/doc/open-governmentlicence/version/3/).

Topographic mapping for Ireland is derived from Ordnance Survey of Ireland Open Data (https://creativecommons.org/licenses/by/4.0/legalcode).

While every effort has been made to contact and obtain permission from holders of copyright, if any involuntary infringement of copyright has occurred, sincere apologies are offered, and the owner of such copyright is requested to contact the publisher.

British Library Cataloguing-in-Publication Data. A catalogue record is available from the British Library.

Design: Alex Donald, Geological Survey of Northern Ireland.

Index: Brendan O'Brien.

Printed in Poland by L\&C Printing Group. 